\title{
Longitudinal trends in prostate cancer incidence, mortality, and survival of patients from two Shanghai city districts: a retrospective population-based cohort study, 2000-2009
}

Yi Hu', Qi Zhao', Jianyu Rao ${ }^{2}$, Haiju Deng ${ }^{3}$, Hong Yuan ${ }^{4}$ and Biao Xu ${ }^{1 *}$

\begin{abstract}
Background: Prostate cancer is the fifth most common cancer affecting men of all ages in China, but robust surveillance data on its occurrence and outcome is lacking. The specific objective of this retrospective study was to analyze the longitudinal trends of prostate cancer incidence, mortality, and survival in Shanghai from 2000 to 2009.

Methods: A retrospective population-based cohort study was performed using data from a central district (Putuo) and a suburban district (Jiading) of Shanghai. Records of all prostate cancer cases reported to the Shanghai Cancer Registry from 2000 to 2009 for the two districts were reviewed. Prostate cancer outcomes were ascertained by matching cases with individual mortality data (up to 2010) from the National Death Register. The Cox proportional hazards model was used to analyze factors associated with prostate cancer survival.

Results: A total of 1022 prostate cancer cases were diagnosed from 2000 to 2009. The average age of patients was 75 years. A rapid increase in incidence occurred during the study period. Compared with the year 2000, 2009 incidence was 3.28 times higher in Putuo and 5.33 times higher in Jiading. Prostate cancer mortality declined from 4.45 per $10^{5}$ individuals per year in 2000 to 1.94 per $10^{5}$ in 2009 in Putuo and from 5.45 per $10^{5}$ to 3.5 per $10^{5}$ in Jiading during the same period. One-year and 5 -year prostate cancer survival rates were $95 \%$ and $56 \%$ in Putuo, and $88 \%$ and $51 \%$ in Jiading, respectively. Staging of disease, Karnofsky Performance Scale Index, and selection of chemotherapy were three independent factors influencing the survival of prostate cancer patients.

Conclusions: The prostate cancer incidence increased rapidly from 2000 to 2009, and prostate cancer survival rates decreased in urban and suburban Chinese populations. Early detection and prompt prostate cancer treatment is important for improving health and for increasing survival rates of the Shanghai male population.
\end{abstract}

Keywords: Prostate cancer, Incidence, Mortality, Survival, China

\section{Background}

Data from the Global Estimates of Cancer 2008 [1] indicate that the age standardized incidence rate (ASR) of prostate cancer in China was 4.3 per $10^{5}$. This rate was much lower than the rates in European and American countries [e.g., United States (ASR of 83.8 per $10^{5}$ )] and was also lower compared with other Asian countries [e.g., Singapore (ASR

\footnotetext{
* Correspondence: bxu@shmu.edu.cn

'Department of Epidemiology, School of Public Health, Key Laboratory of Public Health Safety, Ministry of Education, Fudan University, Shanghai 200032, China

Full list of author information is available at the end of the article
}

of 20.0 per $\left.10^{5}\right)$ ]. Meanwhile, the current increasing trend compared with $2002\left(1.7\right.$ per $\left.10^{5}\right)$ [2] has begun to exceed the rates in some neighboring countries [e.g., India (ASR of 3.4 per $10^{5}$ ), Thailand (ASR of 4.2 per $10^{5}$ ), and Bangladesh (ASR of 1.7 per $\left.10^{5}\right)$ ]. However, because of the limitations of the cancer registration database, there is very limited detailed information on prostate cancer incidence and survival in the Chinese population. Remarkable social and economic development, population aging, and life style changes have occurred in China [3]. Therefore, it is important to identify the observed increasing trends of

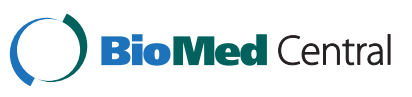

(C) 2014 Hu et al.; licensee BioMed Central Ltd. This is an Open Access article distributed under the terms of the Creative Commons Attribution License (http://creativecommons.org/licenses/by/2.0), which permits unrestricted use, distribution, and reproduction in any medium, provided the original work is properly credited. The Creative Commons Public Domain Dedication waiver (http://creativecommons.org/publicdomain/zero/1.0/) applies to the data made available in this article, unless otherwise stated. 
prostate cancer incidence and treatment outcome in defined geographic populations.

Shanghai is one of the most developed Chinese cities. Vital statistical data have been available for decades, but the Shanghai Cancer Registry has only been in operation since 1972. There is a well-developed, community-based cancer management system in Shanghai, wherein most cancer patients are monitored by local community health providers. The cancer management system facilitates longitudinal prostate cancer trend analysis of incidence, mortality, and survival.

The objective of this study was to describe longitudinal trends of prostate cancer incidence and mortality, to determine survival status, and to identify factor(s) associated with treatment outcomes. Ten years (2000 to 2009) of Cancer Registry data for two Shanghai districts were used for the analysis.

\section{Methods}

\section{Study sites and subjects}

This retrospective population-based cohort study was carried out in Putuo and Jiading, 2 of the 7 districts in Shanghai. The districts were selected retrospectively based on population characteristics and willingness to participate in the study. Putuo is an industrial area with a resident population of 870,046 individuals in 2009 . Jiading is located in a Shanghai suburb and had a population of 546,907 individuals in 2009. The two selected Shanghai areas reflected the composition of the urban and suburban resident populations of the city.

The study subjects were resident prostate cancer patients reported during 2000-2009 in these two districts. Only local Shanghai residents were reported to the Shanghai Cancer Registry. Migrant and temporary residents were not included in the study cohort.

The study protocols were approved by the ethics committee of the School of Public Health, Fudan University (institutional review board-approved protocol number: \#04-03-0011).

\section{Data source}

Information on prostate cancer patients was extracted from three databases (i.e., the Shanghai Cancer Registry, the Shanghai Cancer Follow-up database, and the Shanghai Vital Statistics database at the district Center for Disease Prevention and Control (CDC)). Incident cancer cases were reported by Shanghai hospitals to the district CDC and were registered in the Cancer Registry. The identified cases were verified by community health center personnel, and the follow-up data were managed by the CDC. Information in the Cancer Registry database included the patient's demographic and cancer diagnosis (both clinical and pathologic diagnosis if applicable) data. The cancer-related data included information on disease severity (clinical stage), primary treatment, and active patient follow-up of vital status. Follow-up data included cause of death. To ensure completeness, registry staff validated hospital discharge and death certificate data for registered cases. Prostate cancer death statistics (2000-2010) were extracted from the district CDC Shanghai Vital Statistics database and included age-specific information. The Karnofsky score (KPS) was used to assess quality of life characteristics. The KPS described the ability of each patient to carry out activities on a scale of 0 to $100 \%$. Cancer stage was assessed using the American Urological Association (AUA) prostate cancer staging system [4]. Stages $1-4$ were categorized based on primary tumor size relative to prostate size, and involvement of adjacent structures.

\section{Estimation of incidence and mortality}

Considering the differences in population age structure among countries and among different areas in China, ageadjusted incidence and mortality rates of prostate cancer (for all ages) were calculated using the world standard population age distribution (World Health Organization, 2000) and the national standardized population (China Population Census, 2000). Results were presented as the world standardized rate (WSR) per $10^{5}$ and the national standardized rate (NSR) per $10^{5}$. The mortality/incidence $(\mathrm{M} / \mathrm{I})$ ratio was calculated using the crude and the standardized rates. Relative percentage survival was estimated using $1-\frac{\operatorname{mortality}(M)}{\text { incidence }(I)}$. The ratio, $1-\frac{\mathrm{M}}{I}$, is typically, but not always, a number between 0 and $100 \%$. A value of $0 \%$ indicated extremely poor survival, and a value of $100 \%$ indicated excellent survival [5].

\section{Tests for trends in incidence and mortality}

To estimate the longitudinal prostate cancer trends in the two districts, the estimated annual percentage change (EAPC) and 95\% confidence intervals (CIs) for incidence and mortality were calculated [6,7]. Using calendar year as a regression variable, a linear regression model was applied to describe the overall changes in trend by fitting the parameter using the equation $y=\mathrm{m} x+\mathrm{b}$, where $y$ was $\ln$ (rate), and $x$ was the calendar year. Based on the assumption that the null hypothesis of the $\mathrm{EAPC}=0$ was equivalent to the null hypothesis of the slope of the regression line $=0, \mathbf{E A P C}=\mathbf{1 0 0} \times\left(e^{m}-\mathbf{1}\right)$ and the $95 \% \mathrm{CI}$ of EAPC $=$ $100 \times\left(e^{m \pm S E m}-1\right)$. The standard error of $m(\mathrm{SE} m)$ was obtained from the fit of the regression line. This calculation assumed that the rates increased or decreased at a constant rate over the entire period. Statistical significance was assessed using the two-tailed test at a given test level.

\section{Data analysis of survival}

Yearly and 5-year survival rates after prostate cancer diagnosis were calculated and stratified by disease severity and age at diagnosis. Survival times were measured 
from the date of initial diagnosis to the date of death. Yearly survival rates and effects of prognostic covariates were evaluated using the Kaplan-Meier method and the log-rank test within strata defined by age $(50-59,60-69$, $70-79$, and $\geq 80)$, treatment, and KPS (0-50, 50-80, and $80-100)$ categories. The hazard ratio (HR) and 95\% CI were estimated using a multivariate Cox proportional hazard model. A $p$-value $<0.05$ was considered to be statistically significant. All tests were performed using SPSS 11.0 (SPSS, Chicago, IL, USA).

\section{Results}

\section{Demographic and clinical characteristics of prostate} cancer patients

A total of 1022 (677 in Putuo and 345 in Jiading) prostate cancer cases aged $\geq 20$ years were identified for the 2000-2009 period, with $43.9 \%$ in Putuo and $40.5 \%$ in Jiading under 60 years of age. The median age at diagnosis was 75 years (interquartile range: $71-80$ years) in Putuo and 75 years (interquartile range:68-80 years) in Jiading ( $\mathrm{ICD}-10$ code $=\mathrm{C61})$. For $\mathrm{T}, \mathrm{N}$, and $\mathrm{M}$ staging, there were $69.8 \%, 71.2 \%$, and $69.0 \%$ missing in Putuo and $72.5 \%, 19.7 \%$, and $19.1 \%$ missing in Jiading, respectively. Overall, $39.7 \%, 32.8 \%, 15.2 \%$, and $12.3 \%$ of patients had stage T1, T2, T3, and T4 disease in the Putuo district, and $45.3 \%, 34.7 \%, 11.6 \%$, and $8.4 \%$ of patients had stage $\mathrm{T} 1, \mathrm{~T} 2, \mathrm{~T} 3$, and $\mathrm{T} 4$ disease in the Jiading district, respectively. Tumor cells were present in the regional or distant lymph nodes in $22.1 \%$ of the patients from Putuo and $6.1 \%$ of the patients from Jiading (Table 1). Of the 814 patients (539 in Putuo, 275 in Jiading) for whom staging information was available, the distributions of AUA stages $1-4$ were $25.8 \%, 27.5 \%, 18.0 \%$, and $28.7 \%$ in the Putuo patients, and 27.6\%, 26.5\%, 19.6\%, and $26.3 \%$ in the Jiading patients, respectively.

After diagnosis, $34.4 \%$ (233/677) of the patients from Putuo and 58.6\% (202/345) of the patients from Jiading obtained a prostatectomy, and 141 (20.8\%) and 17 (4.9\%) of the patients received no cancer-specific treatment. The analysis of the vital statistics data received from the district CDCs revealed that 391 (57.8\%) of the patients from Putuo and 188 (54.5\%) of the patients from Jiading were alive in December, 2010.

Trend and point estimation of incidence, mortality, and relative survival

The results for the analysis of longitudinal trends of prostate cancer incidence indicated that there was a remarkable increase in incidence in Putuo and Jiading (Figure 1). In Putuo, the crude incidence rate (CIR) for prostate cancer increased steadily $(\mathrm{EAPC}=13.0 \%$; $95 \%$ CI: 9.6-16.5\%) from 2000-2009. There was a similar total increase in Jiading $(\mathrm{EAPC}=14.1 \%$; 95\% CI: $12.4-$ $15.9 \%)$. However, the increase in Jiading mainly occurred
Table 1 Clinical characteristic of prostate cancer patients during 2000-2009 in Putuo and Jiading

\begin{tabular}{|c|c|c|c|c|}
\hline \multirow[t]{2}{*}{ Variable } & \multicolumn{2}{|c|}{ Putuo $(n=677)$} & \multicolumn{2}{|c|}{ Jiading $(n=345)$} \\
\hline & No. & $\%$ & No. & $\%$ \\
\hline \multicolumn{5}{|c|}{ Vital status at the end of 2010} \\
\hline Alive & 391 & 57.8 & 188 & 54.5 \\
\hline Dead of all causes & 286 & 42.2 & 157 & 45.5 \\
\hline \multicolumn{5}{|l|}{ AUA staging ${ }^{a}$} \\
\hline 1 & 139 & 25.8 & 76 & 27.6 \\
\hline 2 & 148 & 27.5 & 73 & 26.5 \\
\hline 3 & 97 & 18.0 & 54 & 19.6 \\
\hline 4 & 155 & 28.7 & 72 & 26.3 \\
\hline \multicolumn{5}{|l|}{ TNM staging system } \\
\hline \multicolumn{5}{|l|}{ T Stage $^{b}$} \\
\hline $\mathrm{T} 1$ & 81 & 39.7 & 43 & 45.3 \\
\hline $\mathrm{T} 2$ & 67 & 32.8 & 33 & 34.7 \\
\hline T3 & 31 & 15.2 & 11 & 11.6 \\
\hline T4 & 25 & 12.3 & 8 & 8.4 \\
\hline \multicolumn{5}{|l|}{$N$ stage $^{c}$} \\
\hline NO & 152 & 77.9 & 260 & 93.9 \\
\hline N1 & 33 & 16.9 & 12 & 4.3 \\
\hline N2 & 8 & 4.1 & 5 & 1.8 \\
\hline N3 & 2 & 1.1 & 0 & 0.0 \\
\hline \multicolumn{5}{|l|}{ M stage ${ }^{d}$} \\
\hline MO & 151 & 71.9 & 268 & 96.1 \\
\hline M1 & 59 & 28.1 & 11 & 3.9 \\
\hline \multicolumn{5}{|c|}{ Treatment by prostatectomy } \\
\hline None & 141 & 20.8 & 17 & 4.9 \\
\hline Prostatectomy & 233 & 34.4 & 202 & 58.6 \\
\hline Palliative treatment & 26 & 3.9 & 18 & 5.2 \\
\hline Others & 277 & 40.9 & 108 & 31.3 \\
\hline
\end{tabular}

${ }^{\mathrm{a} A U A}$ staging information was missing from 138 patients in Putuo and 70 in Jiading.

${ }^{\text {b } T ~ s t a g i n g ~ i n f o r m a t i o n ~ w a s ~ m i s s i n g ~ f r o m ~} 473$ patients in Putuo and 250 Jiading. ${ }^{c} \mathrm{~N}$ staging information was missing from 482 patients in Putuo and 68 in Jiading. ${ }^{d} M$ staging information was missing from 467 patients in Putuo and 66 in Jiading.

from 2000-2002 and 2008-2009, and there was little change in CIR from 2003-2008. There were similar trends for NSR and WSR. The EAPCs for NSR and WSR were 7.7\% (95\% CI: $4.0-11.5 \%$ ) and 8.5\% (95\% CI: $5.0-12.2 \%)$ in Putuo and 9.1\% (95\% CI: 7.3-11.0\%) and 10.1\% (95\% CI: 8.2-12.0\%) in Jiading, respectively (Table 2).

Prostate cancer mortality rates varied greatly throughout the study period in both of the districts. The highest rate (8.36 per $10^{5}$ ) in Putuo occurred in 2005 (Figure 2). In Jiading, the highest mortality rate $\left(11.25\right.$ per $\left.10^{5}\right)$ occurred in 2002. However, there was a general decrease in trend, with an EAPC of $-33.1 \%$ (95\% CI: -20.1 to $-45.2 \%$ ) in Putuo and $-15.4 \%$ (95\% CI: -10.7 to $-27.4 \%$ ) in Jiading. 


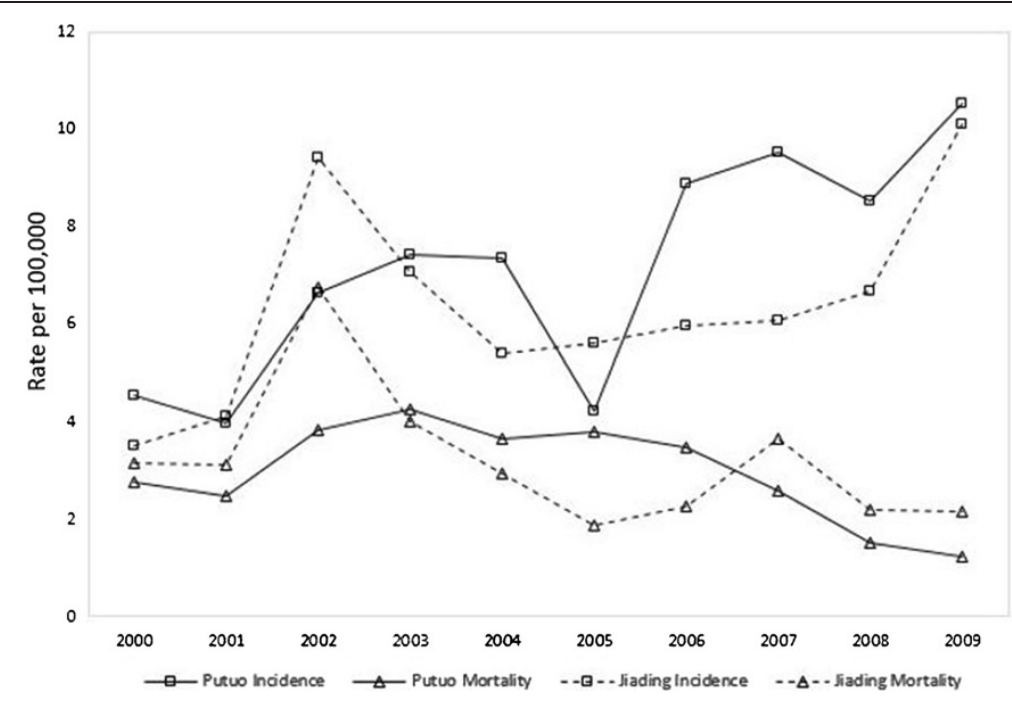

Figure 1 Trend of prostate cancer national standardized rate of incidence and mortality in the male population during 2000-2009.

Similar decreasing trends occurred in NSR values $(-23.8 \%$ in Putuo and $-20.0 \%$ in Jiading) and WSR $(-39.2 \%$ in Putuo and $-10.9 \%$ in Jiading; Table 2).

In general, the relative survival rate increased in both of the districts. The EAPC was $6.2 \%$ for the crude $(95 \%$ CI: $3.8-8.7 \%$ ), NSR (95\% CI: $4.0-9.1 \%)$, and WSR (95\% CI: 4.0-8.4\%) estimates in Putuo and was 5.8\% (95\% CI: 3.9-7.7\%), 6.7\% (95\% CI: 5.4-8.0\%) and 6.7\% (95\% CI: $5.6-7.9 \%)$ for the three estimates, respectively, in Jiading (Table 3).

Throughout the study period, the $60-70$ year age group accounted for the highest proportion of incidence, ranging from $57.0 \%$ in 2004 to $46.0 \%$ in 2009 . A potential increasing trend in incidence occurred in the 50-60 year age group $(\mathrm{EAPC}=40.1 \%$ (95\% CI: $20.0-60.2 \%$ ), and this trend was statistically significant $(p=0.047)$ (Figure 3).

AUA stage 1 and stage 2 cancers accounted for the majority of the estimated incidence values. The highest level of AUA stage 1 occurred in 2009 (47.1\%), and the highest level of AUA stage 2 occurred in 2001 (57.1\%). Meanwhile, there was a steady trend in stage 4 cancer for proportion of incidence $(\mathrm{EAPC}=8 \%$; $95 \%$ CI: 6.9$12.6 \%, p=0.291$ ).

\section{Survival analysis}

The results for analysis of life tables indicated that the respective overall 1-year and 5-year survival rates were

Table 2 Estimated annual percentage change (EAPC) of prostate cancer incidence and mortality during 2000-2009 in Jiading and Putuo

\begin{tabular}{|c|c|c|c|c|c|c|c|c|c|c|}
\hline \multirow[t]{2}{*}{ Rates } & \multicolumn{5}{|c|}{ Putuo district } & \multicolumn{5}{|c|}{ Jiading district } \\
\hline & $\mathrm{M}$ & SEm & EAPC (\%) & $p$ & $95 \% \mathrm{Cl}(\%)$ & $M$ & SEm & EAPC (\%) & $p$ & $95 \% \mathrm{Cl}(\%)$ \\
\hline \multicolumn{11}{|c|}{ Incidence } \\
\hline Crude & 0.122 & 0.031 & 13.0 & $0.005^{a}$ & $9.6 \sim 16.5$ & 0.132 & 0.015 & 14.1 & $0.0001^{a}$ & $12.4 \sim 15.9$ \\
\hline NSR & 0.074 & 0.035 & 7.7 & 0.067 & $4.0 \sim 11.5$ & 0.096 & 0.017 & 9.1 & $0.001^{a}$ & $7.3 \sim 11.0$ \\
\hline WSR & 0.082 & 0.033 & 8.5 & $0.038^{a}$ & $5.0 \sim 12.2$ & 0.087 & 0.017 & 10.1 & $0.0001^{a}$ & $8.2 \sim 12.0$ \\
\hline \multicolumn{11}{|c|}{ Mortality } \\
\hline Crude & -0.402 & 0.328 & -33.1 & 0.253 & $-20.1 \sim-45.2$ & -0.167 & 0.247 & -15.4 & 0.517 & $-10.7 \sim-27.4$ \\
\hline NSR & -0.272 & 0.168 & -23.8 & 0.144 & $-12.7 \sim-41.7$ & -0.223 & 0.148 & -20.0 & 0.172 & $-12.9 \sim-36.7$ \\
\hline WSR & -0.498 & 0.292 & -39.2 & 0.127 & $-23.7 \sim-45.7$ & -0.115 & 0.164 & -10.9 & 0.503 & $-5.2 \sim-24.8$ \\
\hline \multicolumn{11}{|c|}{ Relative survival } \\
\hline Crude & 0.060 & 0.023 & 6.2 & $0.031^{a}$ & $3.8 \sim 8.7$ & 0.056 & 0.018 & 5.8 & $0.013^{a}$ & $3.9 \sim 7.7$ \\
\hline NSR & 0.063 & 0.024 & 6.2 & $0.031^{a}$ & $4.0 \sim 9.1$ & 0.065 & 0.012 & 6.7 & $0.001^{a}$ & $5.4 \sim 8.0$ \\
\hline WSR & 0.060 & 0.021 & 6.2 & $0.02^{a}$ & $4.0 \sim 8.4$ & 0.065 & 0.011 & 6.7 & $0.0001^{a}$ & $5.6 \sim 7.9$ \\
\hline
\end{tabular}

${ }^{a} p<0.05$. 


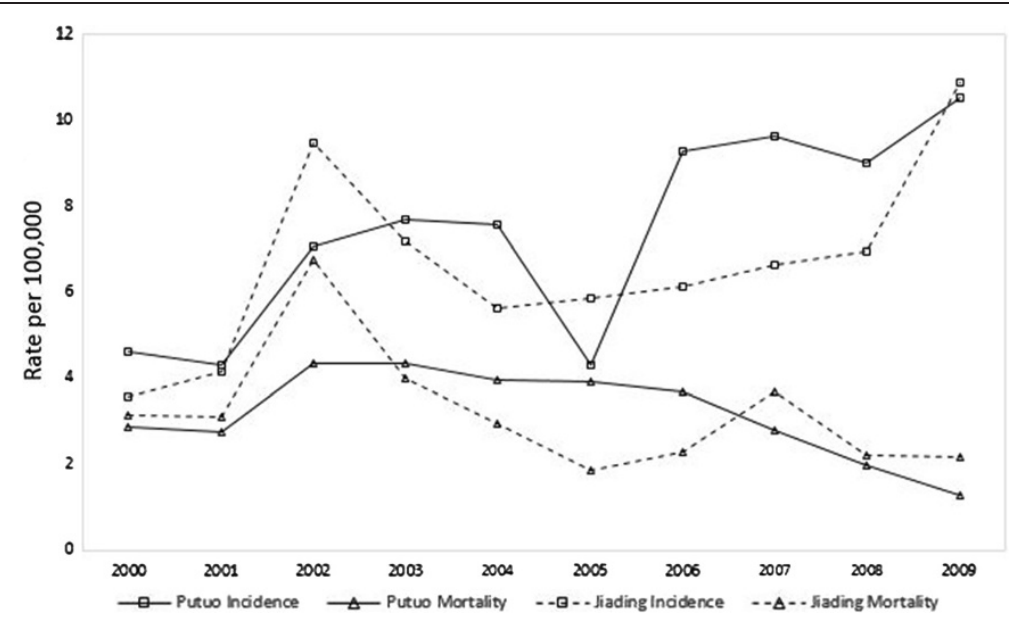

Figure 2 Trend of prostate cancer world standardized rate of incidence and mortality in the male population during 2000-2009.

95\% and 56\% in Putuo, and $88 \%$ and $51 \%$ in Jiading. The log-rank analysis revealed that there were significant differences in prostate cancer survival rate between patients from these two districts $(p=0.043)$. The median survival time was 5.16 years (95\% CI: 5.02-6.18) in Putuo and 5.06 years (95\% CI: 4.94-5.93) in Jiading.
The results of the univariate analysis using log-rank comparisons indicated that cancer stage, age, KPS, and treatment methods were associated with survival. Furthermore, a multivariate analysis using a Cox proportional hazards model revealed that KPS and cancer stage were independent predictive factors for prostate cancer

Table 3 Cox Regression analysis on factors influencing survival of prostate cancer patients diagnosed in 2000-2009 in Jiading and Putuo

\begin{tabular}{|c|c|c|c|c|c|c|}
\hline \multirow[t]{2}{*}{ Variables } & \multirow[b]{2}{*}{ Mean $(95 \% \mathrm{Cl})$} & \multicolumn{2}{|c|}{ Putuo } & \multirow[b]{2}{*}{ Mean $(95 \% \mathrm{Cl})$} & \multicolumn{2}{|c|}{ Jiading } \\
\hline & & HR $(95 \% \mathrm{CI})$ & $p$ & & HR $(95 \% \mathrm{Cl})$ & $p$ \\
\hline \multicolumn{7}{|c|}{ Age at diagnosis (yrs) } \\
\hline $50-$ & $7.6(5.84-9.28)$ & 1 & & $6.1(4.33-7.92)$ & 1 & \\
\hline $60-$ & $6.8(5.87-7.68)$ & $1.4(0.59-3.09)$ & 0.477 & $5.5(4.50-6.42)$ & $1.6(0.49-5.28)$ & 0.438 \\
\hline $70-$ & $6.3(5.84-6.74)$ & $1.5(0.69-3.15)$ & 0.323 & $6.0(5.25-6.69)$ & $1.6(0.50-5.13)$ & 0.428 \\
\hline $80-$ & $4.4(3.88-5.00)$ & $2.4(1.13-5.28)$ & $0.023^{\mathrm{a}}$ & $3.9(3.10-4.61)$ & $2.5(0.75-8.04)$ & 0.138 \\
\hline \multicolumn{7}{|l|}{ AUA Stage } \\
\hline 1 & $6.9(6.05-7.76)$ & 1 & 1 & $7.1(5.97-8.23)$ & 1 & \\
\hline 2 & $7.1(6.16-7.96)$ & $1.0(0.55-1.82)$ & 0.987 & $5.7(4.64-6.69)$ & $1.9(0.70-5.13)$ & 0.209 \\
\hline 3 & $6.6(5.13-8.03)$ & $1.1(0.51-2.36)$ & 0.810 & $4.0(2.89-5.07)$ & $3.0(1.01-8.94)$ & $0.049^{\mathrm{a}}$ \\
\hline 4 & $3.0(2.45-3.56)$ & $3.9(2.33-6.57)$ & $0.0001^{\mathrm{a}}$ & $3.8(2.54-5.08)$ & $2.84(1.03-7.81)$ & $0.044^{\mathrm{a}}$ \\
\hline \multicolumn{7}{|l|}{ Curative treatment } \\
\hline None & $6.4(5.76-7.06)$ & 1 & & $4.1(1.91-6.19)$ & 1 & \\
\hline Prostatectomy & $5.8(5.26-6.38)$ & $1.1(0.76-1.51)$ & 0.696 & $7(6.36-7.62)$ & $0.5(0.19-0.93)$ & $0.026^{\mathrm{a}}$ \\
\hline palliative treatment & 7.1(5.49-8.78) & $0.7(0.30-1.64)$ & 0.419 & $6.1(4.77-7.49)$ & $0.6(0.18-1.81)$ & 0.342 \\
\hline Others & $5.9(5.33-6.49)$ & $1.3(0.94-1.83)$ & 0.106 & $2.7(1.97-3.38)$ & $1.6(0.64-4.12)$ & 0.314 \\
\hline \multicolumn{7}{|l|}{ KPS } \\
\hline $0-$ & $1.3(0.82-1.74)$ & 1 & & $4.6(3.21-5.89)$ & 1 & \\
\hline $50-$ & $3.1(2.29-3.96)$ & $0.6(0.33-1.11)$ & 0.430 & $5.0(3.83-6.19)$ & $0.6(0.26-1.16)$ & 0.118 \\
\hline 80- & $6.6(6.25-6.96)$ & $0.3(0.17-0.48)$ & $0.001^{\mathrm{a}}$ & $5.0(4.41-5.60)$ & $0.8(0.47-1.26)$ & 0.299 \\
\hline
\end{tabular}



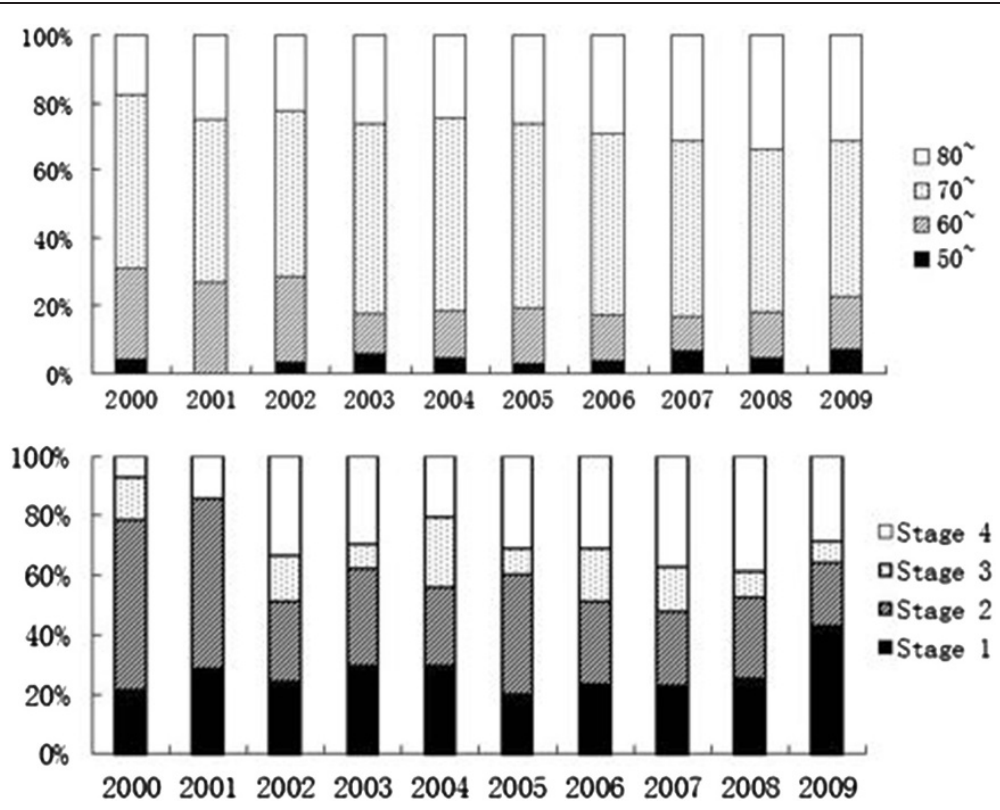

Figure 3 The age and stage stratified distributions of prostate cancer incidence of each year.

survival (Table 3). Patients from Putuo with a KPS value $>80$ had a lower HR for death compared with patients with a KPS value of $0-50$ (HR, 0.3 ; 95\% CI: $0.17-$ 0.48). Compared with stage 1 patients, stage 3 and stage 4 patients from Jiading $\left(\mathrm{HR}_{3}=3.0,95 \% \mathrm{CI}: 1.01-8.94 ; \mathrm{HR}_{4}=\right.$ 2.84, 95\% CI: $1.03-7.81)$ and stage 4 patients from Putuo $\left(\mathrm{HR}_{4}=3.9\right.$, 95\% CI: $\left.2.33-6.57\right)$ had significantly higher HRs for death.

\section{Discussion}

In the 1970s, Shanghai established a cancer registration system that includes the entire resident population. The city-wide cancer registration system documents cancer cases for surveillance, management, and control purposes. The present study used data from this system to determine the longitudinal trends in prostate cancer, including incidence, mortality, and survival status.

The results of this study indicated that there was a trend toward an increased prostate cancer incidence in Shanghai during the past decade. Interpretation of prostate cancer incidence time trends must consider exposure risk factors, population shifts, improvement in case detection, and the impact of PSA screening of asymptomatic patients. The well-established risk factors for prostate cancer are age, race/ethnicity [8], family history $[9,10]$, diet $[11,12]$ and obesity $[13,14]$. Population demographics are changing significantly in China in association with economic development, especially in urban areas. The proportion of men older than age 65 was $6.71 \%$ in Shanghai in 2000 and increased to $16.6 \%$ in 2012. Male life expectancy also increased from 78.77 to 79.82 years. Regardless of age adjustment, this trend indicating increased prostate cancer incidence suggests that the number of prostate cancer cases have increased over the past ten years. There have also been lifestyle changes in the relatively rich cities such as Shanghai, which are reflected by an increased obesity burden. Obesity and overweight have become epidemic in urban populations in China [15], and have been proven to be associated with an increased risk of cancer [16], diabetes [17] and hypertension [18]. The increase in prostate cancer incidence in Shanghai might be attributable to the fat-rich diet consumed by the population.

Technology advances and better access to health care are important for the improvement of cancer detection. The increase in prostate cancer incidence might be a result of the application of echo-guided biopsy and PSA testing in symptomatic or asymptomatic patients. There is currently no active PSA screen program in Shanghai, but PSA testing is widely used, especially in older men who present with urological symptoms. As reflected in this study population, most of the patients who receive PSA testing are symptomatic. The availability of universal health care coverage for Shanghai residents also likely has contributed to the healthcare community's heightened awareness of prostate cancer symptoms. Therefore, changing dietary habits and improved access to health care (including PSA testing) may have contributed to the increased prostate cancer incidence observed in this study. However, the exact contribution of each factor is difficult to quantify.

A relative reduction in mortality from prostate cancer was a finding from our study. This reduction could be explained by improvements in diagnosis and/or early 
detection, and the subsequent use of radical prostatectomy $[19,20]$. The results of our study indicated that there was a trend towards early prostate cancer detection. The proportion of stage 1 cancer was $42 \%$ in 2009 and was $20 \%$ in 2001 . High 5-year survival rates have been reported for localized prostate cancers (stage 1 or 2 ) $[21,22]$, most likely because there are a number of effective treatment options (e.g., radical prostatectomy, radiation). Mortality from high stage disease increases substantially when therapeutic options are rather limited. The results of Scandinavian Prostate Cancer Group Study Number 4 [22] indicated that there was an absolute reduction in mortality of 6 percentage points among men who underwent radical prostatectomy. Similarly, the results of our study suggest that radical prostatectomy reduced prostate cancer mortality. Taken together, these observations indicate that early detection and proper treatment could reduce the prostate cancer mortality. However, overdiagnosis and subsequent treatment may result in side effects (e.g., incontinence and impotence), and adversely affect quality of life.

It was striking to find that compared with the industrial countries that have high rates of survival from prostate cancer, the 1-year and 5-year survival rates were only $95 \%$ and $56 \%$ in Putuo, and $88 \%$ and 51\% in Jiading, respectively. The median survival time was approximately 5 years in both districts. Findings from this analysis also suggest that an initial treatment using prostatectomy and/or chemotherapy may potentially be associated with prolonged survival. Surgery might be effective for the prevention of the spread of prostate cancer. A history of chemotherapy was a predictor that was associated with improved survival in patients undergoing surgery, compared with patients without any treatment. The survival benefit from chemotherapy could be due to tumor cell destruction during prior chemotherapy. Baseline differences in KPS and staging did have an effect on survival. Prostate cancer patients with KPS $\geq 80$ and tumors graded at below a stage 3 were more likely to survive. These characteristics are consistent with less pathologically aggressive disease and a smaller tumor mass [23]. These findings suggest that more efforts should be aimed at early detection of symptomatic patients, and that treatment effects should be verified systematically. Progression in disease pathology should be well documented, and appropriate treatment follow-up is critical.

There has recently been much debate on the need for prostate cancer intervention programs in industrialized countries because it seemed as if early detection and cure were no longer problems in these countries. Almost one-half of the patients included in this study died within five years after diagnosis, which indicates that the value of early detection intervention deserves further discussion. However, most of the patients were older men, so over-diagnosis is a greater concern because of their limited life expectancy. This observation and the findings of the stable trend in incidence in the younger group and the increasing trend in relative survival suggest that a prostate screening program might have limited effects.

The results of this study also revealed that there was an increasing trend in cancer stages 1 and 2. Surgery and chemotherapy do improve survival among prostate cancer patients, and it is likely that treatment with the intention to cure has contributed to the reductions in mortality. Educational programs that instill adequate awareness of early symptoms of prostate cancer in special high risk populations (e.g., males $>70$ years of age) should be developed and implemented. Early prostate cancer detection should improve when the urban population is well-formed.

There were some limitations of this study. Especially for the subjects enrolled in 2009, follow-up time might have not been sufficient for adequate evaluation of outcomes. Therefore, mortality might have been slightly underestimated. The pathological diagnosis (TNM staging) was missing from the records for a relatively high proportion of subjects. Gleason score data were also not included in the registry. Therefore, we were unable to obtain a comprehensive understanding of prostate cancer pathology. Management of the Cancer Registry and Cancer Follow-up databases should be changed so that the quality of the system improves.

\section{Conclusions}

The world population adjusted incidence of prostate cancer was relatively low in the Putuo and Jiading districts of Shanghai in 2009. However, an increase in prostate cancer incidence occurred between 2000 and 2009, which included an estimated annual proportional change of approximately $13.0 \%$ in Putuo and $14.1 \%$ in Jiading. The prostate cancer survival rate was is disappointedly low; the 5-year survival rate was $56 \%$ and $51 \%$ for Putuo and Jiading districts, respectively. Health education on early detection and prompt treatment of prostate cancer is of great importance for improving health and prolonging life of the adult male population in Shanghai.

\section{Competing interests \\ The authors declare that they have no competing interests.}

\section{Authors' contributions}

$B X, Y H$ and $Q Z$ developed the study design. YH, QZ, JR, HD, HY organized the data and conducted the statistical analyses. $\mathrm{YH}$ and $\mathrm{BX}$ were the primary writers of the manuscript and all authors were involved in editing the manuscript. All authors read and approved the final manuscript.

\section{Acknowledgements}

The study was financially supported by a Distinguished Professorship Award to the corresponding author granted by the China Medical Board (No. G16916403), and funding from Sanofi-aventis (China) Investment Co. Ltd for data collection. 


\section{Author details}

${ }^{1}$ Department of Epidemiology, School of Public Health, Key Laboratory of Public Health Safety, Ministry of Education, Fudan University, Shanghai 200032, China. ${ }^{2}$ David Geffen School of Medicine and Jonsson Comprehensive Cancer Center, UCLA, Los Angeles, CA, USA. ${ }^{3}$ Center for Disease Prevention and Control, Putuo District, Shanghai, China. ${ }^{4}$ Center for Disease Prevention and Control, Jiading District, Shanghai, China.

Received: 16 September 2013 Accepted: 9 April 2014

Published: 14 April 2014

\section{References}

1. Ferlay J, Shin HR, Bray F, Forman D, Mathers C, Parkin DM: GLOBOCAN 2008 v2.0, Cancer incidence and mortality worldwide: IARC CancerBase No. 10 [Internet]. Lyon, France: International Agency for Research on Cancer; 2010. Available from: http://globocan.iarc.fr [accessed 23/02/2014].

2. Hsing AW, Devesa SS, Jin F, Gao YT: Rising incidence of prostate cancer in Shanghai, China. Cancer Epidemiol Biomarkers Prev 1998, 7(1):83-84.

3. Ying-Xiu Z, Shu-Rong W: Secular trends in body mass index and the prevalence of overweight and obesity among children and adolescents in Shandong, China, from 1985 to 2010. J Public Health (Oxf) 2012, 34(1):131-137

4. : American Urological Association releases guidelines for the management of localized prostate cancer. Am Fam Physician 1996, 53(8):2751-2752.

5. Ladjevardi S, Sandblom G, Berglund A, Varenhorst E: Tumour grade, treatment, and relative survival in a population-based cohort of men with potentially curable prostate cancer. Eur Urol 2010, 57(4):631-638.

6. Abdollah F, Gandaglia G, Thuret R, Schmitges J, Tian Z, Jeldres C, Passoni NM, Briganti A, Shariat SF, Perrotte P, Montorsi F, Karakiewicz PI, Sun M: Incidence, survival and mortality rates of stage-specific bladder cancer in United States: a trend analysis. Cancer Epidemiol 2013, 37(3):219-225.

7. Nygard M, Aagnes B, Bray F, Moller B, Mork J: Population-based evidence of increased survival in human papillomavirus-related head and neck cancer. Eur J Cancer 2012, 48(9):1341-1346.

8. Zeigler-Johnson CM, Rennert H, Mittal RD, Jalloh M, Sachdeva R, Malkowicz SB, Mandhani A, Mittal B, Gueye SM, Rebbeck TR: Evaluation of prostate cancer characteristics in four populations worldwide. Can J Urol 2008, 15(3):4056-4064.

9. Hemminki K: Familial risk and familial survival in prostate cancer. World $J$ Urol 2012, 30(2):143-148.

10. Brandt A, Sundquist J, Hemminki K: Risk for incident and fatal prostate cancer in men with a family history of any incident and fatal cancer. Ann Oncol 2012, 23(1):251-256.

11. Huang $M$, Narita $S$, Numakura $K$, Tsuruta $H$, Saito M, Inoue T, Horikawa $Y$, Tsuchiya N, Habuchi T: A high-fat diet enhances proliferation of prostate cancer cells and activates MCP-1/CCR2 signaling. Prostate 2012, 72(16):1779-1788

12. Marshall JR: Diet and prostate cancer prevention. World J Urol 2012, 30(2):157-165.

13. Lughezzani G: The relationship between obesity and prostate cancer: from genetics to disease treatment and prevention. BMC Med 2012, 10:109.

14. Fowke JH, Motley SS, Concepcion RS, Penson DF, Barocas DA: Obesity, body composition, and prostate cancer. BMC Cancer 2012, 12:23.

15. Wang H, Wang J, Liu MM, Wang D, Liu YQ, Zhao Y, Huang MM, Liu Y, Sun J, Dong GH: Epidemiology of general obesity, abdominal obesity and related risk factors in urban adults from 33 communities of Northeast China: the CHPSNE study. BMC Public Health 2012, 12:967.

16. Wang $D$, Zheng W, Wang SM, Wang JB, Wei WQ, Liang H, Qiao YL, Boffetta $P$ : Estimation of cancer incidence and mortality attributable to overweight, obesity, and physical inactivity in China. Nutr Cancer 2012, 64(1):48-56.

17. Shen J, Goyal A, Sperling L: The emerging epidemic of obesity, diabetes, and the metabolic syndrome in China. Cardiol Res Pract 2012, 2012:178675.

18. Li X, Xu J, Yao H, Guo Y, Chen M, Lu W: Obesity and overweight prevalence and its association with undiagnosed hypertension in Shanghai population, China: a cross-sectional population-based survey. Front Med 2012, 6(3):322-328.
19. Schroder FH, Hugosson J, Roobol MJ, Tammela TL, Ciatto S, Nelen V, Kwiatkowski M, Lujan M, Lilja H, Zappa M, Denis LJ, Recker F, Paez A, Maattanen L, Bangma CH, Aus G, Carlsson S, Villers A, Rebillard X, van der Kwast T, Kujala PM, Blijenberg BG, Stenman UH, Huber A, Taari K, Hakama M, Moss SM, de Koning HJ, Auvinen A: Prostate-cancer mortality at 11 years of follow-up. N Engl J Med 2012, 366(11):981-990.

20. Sarma AV, Schottenfeld D: Prostate cancer incidence, mortality, and survival trends in the United States: 1981-2001. Semin Urol Oncol 2002, 20(1):3-9.

21. Abdollah F, Sun M, Schmitges J, Thuret R, Bianchi M, Shariat SF, Briganti A, Jeldres C, Perrotte P, Montorsi F, Karakiewicz PI: Survival benefit of radical prostatectomy in patients with localized prostate cancer: estimations of the number needed to treat according to tumor and patient characteristics. J Urol 2012, 188(1):73-83.

22. Vickers A, Bennette C, Steineck G, Adami HO, Johansson JE, Bill-Axelson A, Palmgren J, Garmo H, Holmberg L: Individualized estimation of the benefit of radical prostatectomy from the Scandinavian Prostate Cancer Group randomized trial. Eur Urol 2012, 62(2):204-209.

23. Hennenfent BR: Pathological staging and biochemical recurrence after neoadjuvant androgen deprivation therapy in combination with radical prostatectomy in clinically localized prostate cancer. Br J Urol 1998, 82(1):166.

doi:10.1186/1471-2458-14-356

Cite this article as: Hu et al:: Longitudinal trends in prostate cancer incidence, mortality, and survival of patients from two Shanghai city districts: a retrospective population-based cohort study, 2000-2009. BMC Public Health 2014 14:356.

\section{Submit your next manuscript to BioMed Central and take full advantage of:}

- Convenient online submission

- Thorough peer review

- No space constraints or color figure charges

- Immediate publication on acceptance

- Inclusion in PubMed, CAS, Scopus and Google Scholar

- Research which is freely available for redistribution

Submit your manuscript at www.biomedcentral.com/submit
C) Biomed Central 